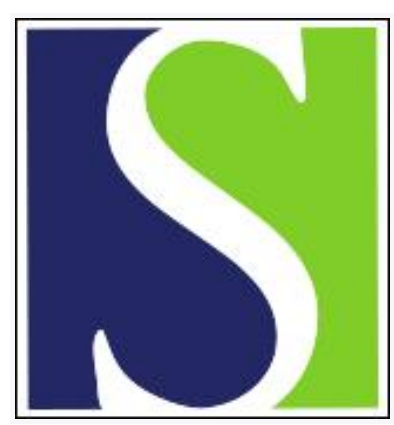

Scand J Work Environ Health 1986;12(2):81-96

https://doi.org/10.5271/sjweh.2162

Issue date: Apr 1986

In vivo elemental analysis in occupational medicine.

by Scott MC, Chettle DR

This article in PubMed: www.ncbi.nlm.nih.gov/pubmed/3726499

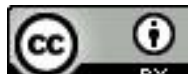




\title{
In vivo elemental analysis in occupational medicine
}

\author{
by Malcolm C Scott, PhD, David R Chettle, $\mathrm{PhD}^{1}$
}

\begin{abstract}
SCOTT MC, CHETTLE DR. In vivo elemental analysis in occupational medicine. Scand J Work Environ Health 12 (1986) 81-96. The application of in vivo measurement techniques, derived from nuclear and atomic physics, to problems encountered in occupational medicine is discussed. The main techniques, neutron activation and X-ray fluorescence, are described, and their use for in vivo measurements of cadmium and lead is explored in some detail. The extension of these and other, related, techniques to the possible measurement of other elements of importance in occupational medicine is considered. The use of in vivo measurements as a tool for research into the toxicological effects of cadmium, associated with occupational exposure is taken as an example of the way in which in vivo elemental analysis can contribute to research in occupational medicine.
\end{abstract}

Key terms: cadmium, lead, mercury, neutron activation analysis, X-ray fluorescence.

The increasing sophistication of techniques used for the biochemical analysis of blood and urine means that those studying occupational health have at their disposal a wide, and growing, range of indicators of health status. Consequently, the effect of potentially toxic elements can be monitored in increasing detail. However, the interpretation of these measurements requires knowledge of body stores and turnover of the element of interest. Until a decade or so ago, such information could only be obtained by biopsy or autopsy analysis. As is well known, each of these methods has quite severe limitations, and therefore neither technique lends itself to the kind of broad-ranging, largesample survey which is desirable in order to obtain as complete a picture as possible of occupationally related health effects.

More recently, however, a number of nuclear and atomic techniques have been developed which enable in vivo elemental analysis to be undertaken for a range of elements which, though limited, includes at least two toxic heavy metals that give rise to considerable concern occupationally, namely, cadmium and lead.

To date, two techniques for in vivo analysis have undergone extensive development, namely, neutron activation analysis (NAA) and X-ray fluorescence (XRF), and both are now used world-wide, albeit still at specialist centers. However sufficient work has now been undertaken that their use could be more widely disseminated. In this paper we therefore discuss the principles of these and related techniques and review their application to elements of potential interest as far as occupational exposure is concerned.

\section{Department of Physics, University of Birmingham, Bir- mingham, England.}

Reprint requests to: Dr MC Scott, Department of Physics, University of Birmingham, PO Box 363 , Birmingham Bl5 2TT, England.

\section{Experimental principles}

Both neutron activation analysis and X-ray fluorescence depend on the detection of photons generated in the element of interest by an externally incident beam of radiation. In the case of neutron activation analysis, the irradiation is performed by neutrons, and the detected photons are gamma rays given off following neutron-nuclear interactions. In contrast, photon emission in X-ray fluorescence is produced by an incident beam of $X$ rays or gamma rays interacting with the atomic electrons of the element concerned, resulting in the emission of characteristic $X$ rays. The only in vivo method not using photon detection is the detection of beryllium $(\mathrm{Be})$, where use is made of the fact that high-energy photons can cause photoneutron production in beryllium. Detection of the neutrons produced then forms the basis for the analysis technique.

Because the principles and procedures for neutron activation analysis and $\mathrm{X}$-ray fluorescence are so widely different, we have considered them separately.

\section{Neutron activation analysis}

Neutrons are normally produced using nuclear reactors, particle accelerators, or radioisotopes. Although the range of neutron energies which can be obtained is wide (16), the minimum energy obtainable is in the kiloelectronvolt region. Such neutrons are available from filtered beams in nuclear reactors or from $(\gamma, n)$ radioisotope sources. However, the former are very specialized and are only available at a few centers in the world, while the latter are accompanied by such intense gamma ray fields (typically greater than $10^{4}$ gamma rays per neutron) that their use for in vivo analysis is impractical. Consequently, the majority of the neutron sources used are either radioisotopes spontaneous fission or $\mathrm{Be}(\alpha, \mathrm{n})$ - or low- to medium- 
energy particle accelerators. From both of these sources the characteristic neutron energies are in the low megaelectronvolt energy range (normally called "fast" neutrons).

Neutrons in the megaelectronvolt range can be used for elemental analysis, since gamma rays can be emitted following a range of neutron interactions,

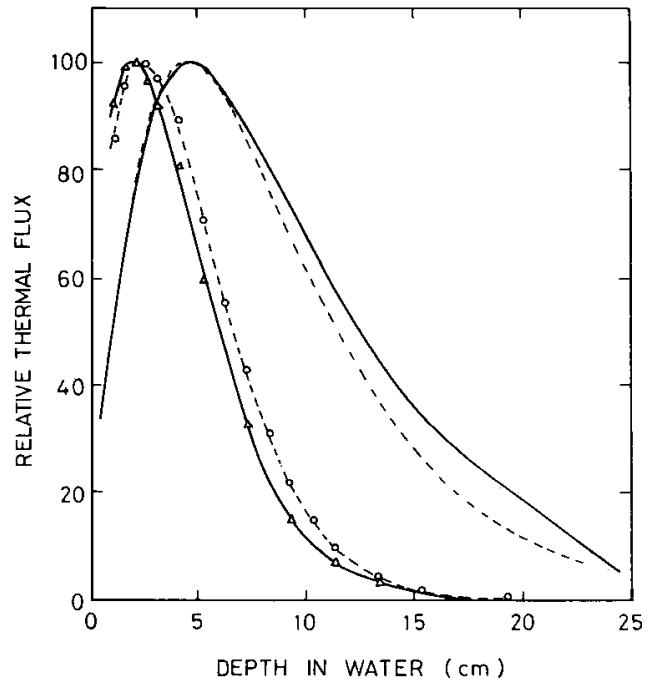

Figure 1. Thermal neutron distributions for different energy neutron sources (40). ( $-{ }^{238}$ plutonium, beryllium; $--{ }^{252}$ californium; $\Delta-\Delta 2 \mathrm{keV} ; 0 \ldots \ldots 24 \mathrm{keV}$ )

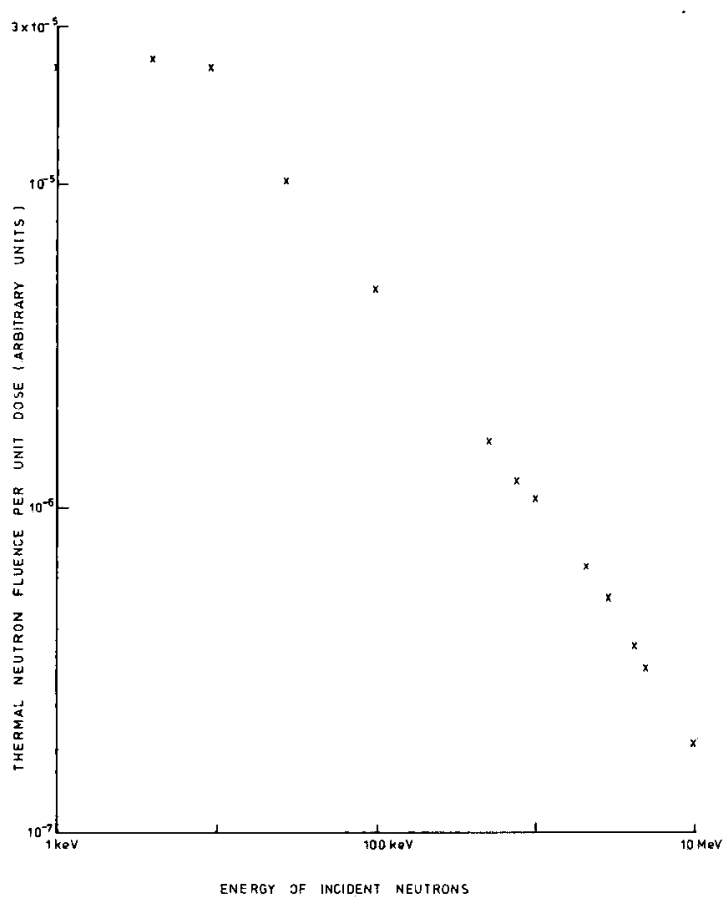

Figure 2. Thermal neutron fluence per unit dose at a typical kidney depth calculated for different neutron energies (47). either promptly (ie, at the time of interaction) or following radioactive decay of a radionuclide formed by the interaction. The interactions concerned include neutron inelastic scattering $[n, n ' \gamma)]$, charged particle emission $[\mathrm{eg},(\mathrm{n}, \alpha)$ and $(\mathrm{n}, \mathrm{p})]$, and multiple neutron production $[(\mathrm{n}, 2 \mathrm{n})]$. A range of elements has been measured using these reactions. A general review of such applications has been undertaken by Cohn (17), and the experimental techniques have been reviewed by Chettle \& Fremlin (13). However, of the elements concerned, ie, oxygen (O), nitrogen (N), calcium (Ca), silicon ( $\mathrm{Si})$, iron ( $\mathrm{Fe}$ ), and phosphorus (P), although some are relevant in the context of occupational health, the sensitivity is not sufficiently high for many occupational health problems of interest. An alternative way of stating this is that for many elements the radiation dose involved is currently too high to justify the application of the techniques involved as a routine research procedure because the benefit to the subject is not clearly demonstrable. At the same time, we note that, when elements pose particular, and widespread, occupational health problems, eg, exposure to silicon, the development of in vivo analysis techniques involving higher radiation exposures could be justified. We have discussed silicon measurement techniques later in this paper.

In interacting with nuclei - particularly the light ones like those of hydrogen $(\mathrm{H})$ and carbon $(\mathrm{C})$ neutrons lose energy and slow down by elastic or inelastic nuclear scattering and eventually come into thermal equilibrium with the medium concerned, their characteristic energies then being in the millielectronvolt range. At these energies, the neutron capture cross section for most elements, and their isotopes, increases as the neutron energy decreases [specifically, the cross section $(\sigma)$ is inversely proportional to the neutron velocity]. Following neutron capture, gamma rays are emitted with energies characteristic of the nucleus con-

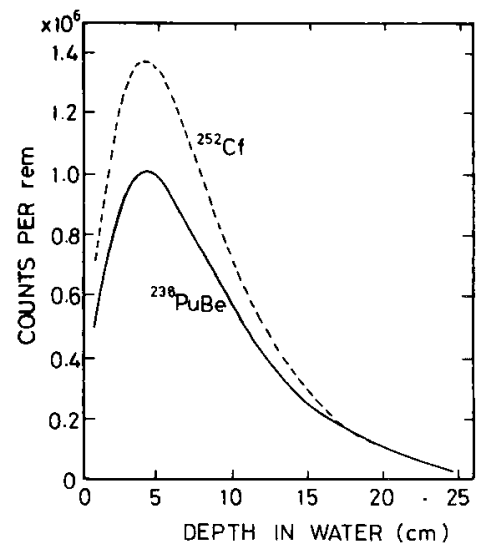

Figure 3. Thermal neutron fluence per unit dose. Effect on sensitivity for two isotopic neutron sources as a function of organ position (40). (1 rem $=10^{-2} \mathrm{~Sv}, \mathrm{Cf}=$ californium, PuBe $=$ plutonium-beryllium) 
cerned. However, there must be one gamma ray with a high probability of being produced if the resulting signal is to be seen against the background present in any neutron irradiation.

Because the distribution of first neutron collisions in the subject falls roughly exponentially from the subject's skin surface, and because the slowing down and thermalization process is accompanied by significant migration from the site where the incident (fast) neutron has its first collision within the body, the distribution of thermal neutrons in the subject is far from uniform. This can be seen from figure 1 , where it can be seen that, in a water phantom, the peak thermal neutron flux occurs at 3 to $6 \mathrm{~cm}$ from the surface and that the peak moves deeper as the incident neutron energy increases. Consequently, except in small organs like the kidney, it may be difficult to obtain a uniform thermal neutron field, and for toxic elements whose distribution is over a large volume the nonuniformity of neutron distribution can be a factor limiting measurement accuracy. In particular, of course, if the organ is not in a region of peak flux, the ratio of gamma-ray signal to neutron dose may not be maximized, and the measurement sensitivity for a given radiation dose is reduced.

The thermal neutron flux per unit dose also varies with both neutron energy and organ position, as can be seen from figures 2 and 3. Consequently, the choice of source and irradiation regime is dictated by the depth and extent of the organ concerned. As far as the outgoing gamma rays are concerned, they are attenuated exponentially through any tissue between their point of origin and the detector, and their measured intensity also falls as $1 / r^{2}$, where $r$ is the distance to the detector. Consequently, one wants to site the detector as near the organ being measured as possible and with a minimum of intervening tissue. In practice, the geometry is normally constrained by the need to shield the detector from neutrons. It is also constrained by the need to shield both the subject and others in the vicinity from neutrons outside the collimated beam and to shield the detector from gamma rays produced in the resulting neutron shielding. For these reasons, neutron activation assemblies are both bulky and heavy. Nevertheless, they can be made transportable, like those at Brookhaven and Birmingham, for example, and figure 4 shows one such system.

\section{$X$-ray fluorescence}

Both the principle and experimental implications are simpler for X-ray fluorescence than for neutron activation analysis. Photons (normally either gamma rays or X rays) interacting with an atom through the photoelectric process can eject a tightly bound, inner-shell electron from the atom. The movement of outer-shell electrons inwards to fill the resulting vacancy is accompanied by the emission of $\mathrm{X}$ rays of a range of ener- gies, the combination of which is unique to the element concerned. This process is shown schematically in figure 5 . The $X$ rays associated with transitions to the $\mathrm{K}$ shell - the $\mathrm{K}_{\alpha}$ and $\mathrm{K}_{\beta}$ lines - are the most energetic and therefore the most penetrating.

The characteristic $\mathrm{K} X$-ray energies vary from fractions of a kiloelectronvolt, in the light elements, to over $100 \mathrm{keV}$ for the actinides. However, because lowenergy $\mathrm{X}$ rays are rapidly attenuated, the detection of $X$ rays from other than superficial body sites is re-
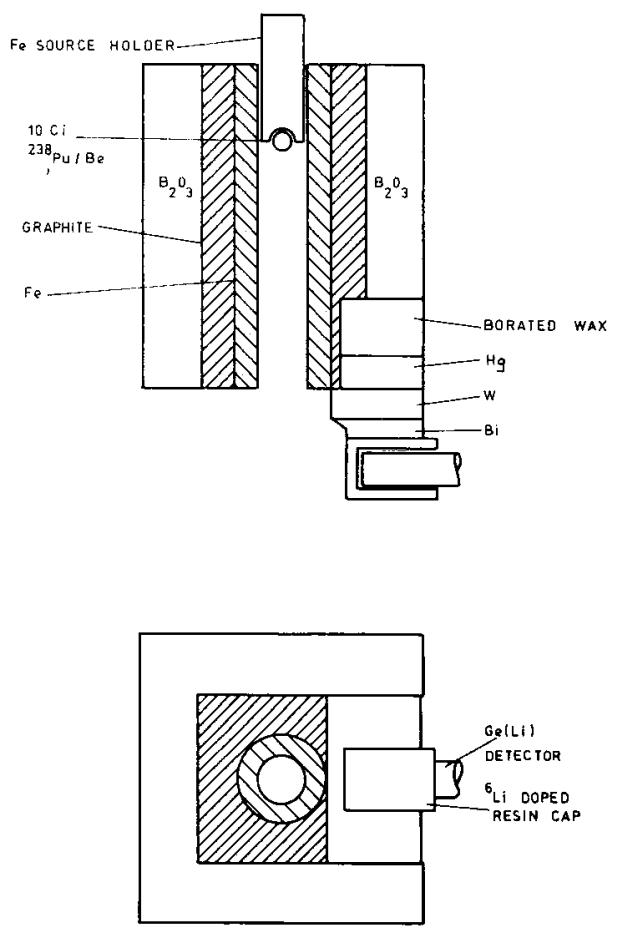

Figure 4. Example of a transportable cadmium measurement apparatus - The Birmingham liver measurement system. $\left(\mathrm{Fe}=\right.$ iron, $\mathrm{Pu}=$ plutonium, $\mathrm{Be}=$ beryllium, $\mathrm{B}_{2} \mathrm{O}_{3}=$ boric oxide, $\mathrm{Hg}=$ mercury, $\mathrm{W}=$ tungsten, $\mathrm{Bi}=$ bismuth, $\mathrm{Ge}=$ germanium, $\mathrm{Li}=$ lithium, $1 \mathrm{Ci}=3.7 \cdot 10^{10} \mathrm{~Bq}$ )

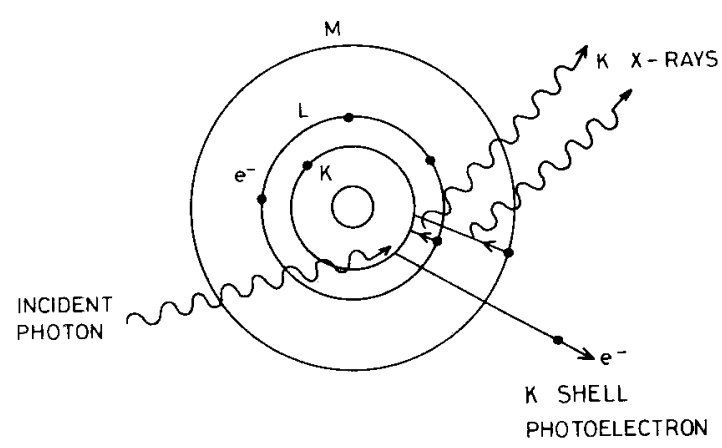

Figure 5. Principle of $\mathrm{X}$-ray fluorescence. (M, L and $\mathrm{K}$ mark the various electron energy levels). 
stricted to the higher $\mathrm{Z}$ elements, which have the added advantage of a higher $\mathrm{X}$-ray fluorescence yield; for example, measurements of iron ( $\mathrm{K}_{\alpha_{1}}$ energy $6.4 \mathrm{keV}$ ) can only be made at depths of a few millimeters unless high radiation doses are acceptable.

Clearly both the incident photons and the outgoing $X$ rays will be attenuated by intervening tissue, and the detected X-ray intensities will, as with neutrons, vary from the point of origin as $1 / \mathrm{r}^{2}$. Thus minimizing source-to-organ and organ-to-detector distances is important in maximizing the ratio of the measured X-ray signal to the incident photon dose. However, the constraint on geometry in the $\mathrm{X}$-ray case is imposed by the fact that the main detector background arises from incident photons being Compton-scattered in the subject. The energy of these photons is strongly angular dependent so that the position of the Compton scatter peak relative to the $\mathrm{X}$-ray peak(s) of interest depends on the source-subject-detector angle (the "detection angle'). In addition, the detector response function is not symmetrical, but has a significant low-energy component, which can increase the signal-to-background ratio if the Compton scatter peak is above, rather than below, the X-ray peak of interest. These factors have been discussed in detail by Somervaille et al (50).

In contrast to the case with neutrons, no very severe constraints are imposed by shielding considerations, since photons of $100 \mathrm{keV}$ or less are easily attenuated by a few millimeters of heavy metal, eg, tungsten alloy. Clearly, however, any shielding material should not produce $\mathrm{X}$-ray peaks interfering with those of interest. A typical set up will therefore have a source, or sources, of photons irradiating the organ concerned, with either a lithium-drifted silicon [Si(Li)], lithium-drifted germanium [ $\mathrm{Ge}(\mathrm{Li})]$, or a hyperpure germanium detector ( $\mathrm{Ge} \mathrm{Hp}$ ) to detect the $\mathrm{X}$ rays. The position of the detector is determined by the energy and permissible energy spread of the Comptonscattered photons and by any collimation requirements. For a given geometry, the Compton scatter energy is, in turn, determined by the source photon energy, so that one has to specify both the source and element of interest before a geometry can be determined. It then follows that a given set-up may not be optimal for a wide range of elements in a particular organ or site, whereas the use of neutrons is a little more flexible in this respect.

Because of the strong attenuation of both incident and outgoing photons, the relative detection efficiency of X-ray fluorescence varies even more strongly with position in the subject than it does with neutrons. Consequently, the problem of relating a measured photon intensity to an in vivo concentration of the element of interest may be more difficult for X-ray fluorescence than for neutron activation analysis. There is, however, one notable exception, namely, lead, and we have discussed it in more detail in dealing with specific measurements.

\section{In vivo measurements}

Although studies, or actual in vivo measurements, have been made for a number of elements, most of the work in occupational medicine so far has concentrated on cadmium and, to an increasing extent, on lead. We therefore now consider measurements of these two elements in more detail.

\section{Cadmium}

Measurement using neutron activation. Cadmium (Cd) can be measured in vivo in kidney, one of the two principle organs of accumulation, by both neutron activation analysis and X-ray fluorescence. The other organ of accumulation, the liver, is normally only measured by neutron activation analysis, because the cadmium concentration, expressed in micrograms per gram of wet tissue, is much lower than in the kidney, and the organ is a large one, giving rise to nonuniform detection efficiency and low sensitivity (for a given radiation dose) if $\mathrm{X}$-ray fluorescence is used.

With neutron activation analysis the measurement relies on the detection of the $559 \mathrm{keV}$ gamma rays emitted promptly $\left(\sim 10^{-11} \mathrm{~s}\right)$ as part of the capture gamma-ray spectrum when thermal neutrons are captured in ${ }^{113} \mathrm{Cd}$. The latter is $12.26 \%$ abundant and is distinguished by having an extremely large thermal neutron capture cross section (19 910 barns, compared to a barn or so for most other body elements).

Because, as we have noted, all neutron sources whether from fission or radioisotopes via $(\alpha, n)$ or $(\gamma, n)$ reactions - have energies in the kilo- and megaelectronvolt regions, it is necessary to slow such neutrons down to thermal energies (ie, energies comparable to those of their surroundings, typically $0.025 \mathrm{eV}$ ) in order to take advantage of the very large ${ }^{113} \mathrm{Cd}$ capture cross section. This neutron thermalization, as it is called, normally takes place in the body of the subject, mainly through neutron elastic scattering interactions with hydrogen. The advantage is that, as we have noted earlier, the peak thermal neutron flux is then some distance inside the body. Were the neutrons to be thermalized outside the body, the peak thermal flux on the subject would be on the skin surface, and the intensity would die away exponentially from the surface. This would result in a low and nonuniform thermal neutron flux at organs of interest inside the body.

The lithium-drifted, or hyperpure, germanium detectors normally used for measuring the $559-\mathrm{keV}$ cadmium gamma rays are sensitive to fast neutrons, and their energy resolution deteriorates with increasing neutron fluence (total number of neutrons incident per unit area). For this reason, the detector has to be shielded from direct-source neutrons as efficiently as possible. It also has to be shielded from gamma rays produced by neutron interactions anywhere in the assembly, since the background which these would 
constitute worsens the measurement sensitivity. It is, of course, also necessary to shield the subject from neutrons other than in the collimated beam and to minimize the radiation dose to the staff operating the facility. One such experimental arrangement is shown in figure 4. This is for measurement of liver cadmium and uses a $10-\mathrm{Ci}(0.37 \mathrm{TBq}){ }^{238} \mathrm{Pu}-\mathrm{Be}\left({ }^{238}\right.$ plutoniumberyllium) neutron source (Amersham International, type PPNW 398). The assembly, which weighs about $100 \mathrm{~kg}$, can be taken apart for transportation. The corresponding kidney cadmium system uses two $20-C i$ $(0.74 \mathrm{TBq}){ }^{238} \mathrm{Pu}-\mathrm{Be}$ neutron sources and, because of the increased shielding required, weighs about twice as much. The detector used on the liver system is a single $\mathrm{Ge}(\mathrm{Li})$ crystal. However, the development of n-type hyperpure germanium detectors, which have greater resistance to radiation damage, means that these are preferable, albeit more expensive.

The overall system performance depends primarily upon the incident neutron spectrum and the number and size of the detectors. However, for a given detector, the factors affecting measurement sensitivity are (i) the source-subject and organ-detector distance, (ii) the depth of tissue overlying the organ concerned along the paths of both the incident neutrons and the outgoing gamma rays, (iii) the gamma-ray and neutron background at the detector, and (iv) the incident neutron spectrum. In practice, for the type of arrangement shown and using ${ }^{238} \mathrm{Pu}$-Be neutron sources, the sensitivity of the Birmingham systems are $6.5 \mu \mathrm{g} \cdot \mathrm{g}^{-1}$ for cadmium in liver and $6.4 \mathrm{mg}$ of cadmium in the kidney for average organ depths. The characteristics of several different measurement systems have been compared by Morgan et al (40), and table 1 shows a similar comparison using more recent data. We note that the units used for measurement are different because of the differences in organ size. For kidney the total content can be measured because the whole organ can be irradiated in a single measurement, whereas the liver is too big for this, so only a portion can be irradiated. In practice, stronger sources are sometimes used for kidney measurements, because of the lower total cadmium in the measurement volume. Otherwise, measurement times would be too long; they are normally $20-40 \mathrm{~min}$.

Because of the importance of overlying tissue in determining the thermal neutron flux at the liver or kidney, depth-dependent corrections have to be made to relate organ-like phantom measurements to an in vivo determination. The normal method of measuring liver or kidney depth is to use ultrasound, and figures $6 \mathrm{a}$ and $6 \mathrm{~b}$ show both the variation in cadmium detection efficiency with tissue depth in a water phantom and the range of organ depths found in one of our surveys. We note that ultrasound can also be used to estimate organ volume (39).

The radiation doses involved in each of these measurements are comparable with those involved in a normal chest radiograph. For the Birmingham system, these doses correspond to skin doses of $0.5 \mathrm{mSv}$ (50 mrem) for the liver measurement and $0.9 \mathrm{mSv}$ (90 mrem) for the kidney, while those for other systems are given in table 1. For these measurements, the main radiation dose comes from fast neutrons, which produce recoil protons on interaction with hydrogen. The doses from the resulting gamma rays and from neutron-induced radioactivity are negligibly small (39). In estimating these doses, the various authors concerned have taken a quality factor for fast neutrons of 10 . We note from table 1 that the whole-body equivalent doses of $30 \mu \mathrm{Sv}$ ( $3 \mathrm{mrem}$ ) and $54 \mu \mathrm{Sv}$ (5.4 mrem) for our system are within of the World Health Organization's category I for research project irradiations of $0.5 \mathrm{mSv}$ ( $50 \mathrm{mrem}$ ), and that the level of risk is thus classed as being "within variations of natural background radiation" (62).

Table 1. Summary of the characteristics of the neutron-based systems used to measure cadmium in liver and kidney. ( $\mathrm{Am}=$ americium, $\mathrm{Be}=$ beryllium, $\mathrm{Pu}=$ plutonium, $\mathrm{Cf}=$ californium)

\begin{tabular}{|c|c|c|c|c|c|c|c|c|}
\hline Laboratory & Organ & $\begin{array}{l}\text { Neutron } \\
\text { source }\end{array}$ & $\begin{array}{l}\text { Skin dose } \\
(\mathrm{mSv})^{\mathrm{a}}\end{array}$ & $\begin{array}{l}\text { Number of } \\
\text { detectors }\end{array}$ & $\begin{array}{c}\text { Detection } \\
\text { efficiency } \\
(\%)\end{array}$ & $\begin{array}{l}\text { Lower } \\
\text { limit of } \\
\text { detection }\end{array}$ & $F^{c}$ & Reference \\
\hline Baghdad & Liver & ${ }^{241} \mathrm{Am}-\mathrm{Be}$ & 1.0 & 1 & 3 & $20 \mu \mathrm{g} \cdot \mathrm{g}^{-1}$ & 35 & \multirow{9}{*}{$\begin{array}{l}\text { Al-Hiti et al (4) } \\
\text { Chettle et al (12) } \\
\text { Krauel et al (31) } \\
\text { Ellis et al (22) } \\
\text { Personal } \\
\text { communication } \\
\text { McNeill et al (35) } \\
\text { Chettle \& Fremlin (13) } \\
\text { Ellis et al (22) } \\
\text { Personal } \\
\text { communication }\end{array}$} \\
\hline Birmingham & Liver & ${ }^{238} \mathrm{Pu}-\mathrm{Be}$ & 0.5 & 1 & 14 & $4.6 \mu \mathrm{g} \cdot \mathrm{g}^{-1}$ & 12 & \\
\hline Brisbane & Liver & ${ }^{238} \mathrm{Pu}-\mathrm{Be}$ & 1.0 & 1 & 13.5 & $6.7 \mu \mathrm{g} \cdot \mathrm{g}^{-1}$ & 25 & \\
\hline Brookhaven & Liver & ${ }^{252} \mathrm{Cf}$ & 2.0 & 2 & 25 & $1.5 \mu \mathrm{g} \cdot \mathrm{g}^{-1}$ & 15 & \\
\hline Swansea & Liver & ${ }^{252} \mathrm{Cf}$ & 3.5 & 2 & 20 & $1.3 \mu \mathrm{g} \cdot \mathrm{g}^{-1}$ & 15 & \\
\hline Toronto & Liver & ${ }^{252} \mathrm{Cf}$ & & 1 & 10 & $10 \mu \mathrm{g} \cdot \mathrm{g}^{-1}$ & 48 & \\
\hline Birmingham & Kidney & 238Pu-Be & 0.9 & 2 & 14 & 4.5 & 23 & \\
\hline Brookhaven & Kidney & ${ }^{252} \mathrm{Cf}$ & 2.0 & 2 & 25 & 2.2 & 22 & \\
\hline Swansea & Kidney & ${ }^{252} \mathrm{Cf}$ & 3.5 & 2 & 20 & 1.9 & 23 & \\
\hline
\end{tabular}

a The relationship between organ and skin dose depends on the source used and the geometric configuration. Whole body dose equivalents range from $30-210 \mu$ Sv per organ; the upper limit of category I of the World Health Organization is $500 \mu \mathrm{Sv}$.

b Corresponding to a peak two times the standard error of the underlying background.

c $F($ an index of performance $)=$ lower limit of detection $\times$ number of detectors $\times$ detection efficiency $\times$ skin dose. 

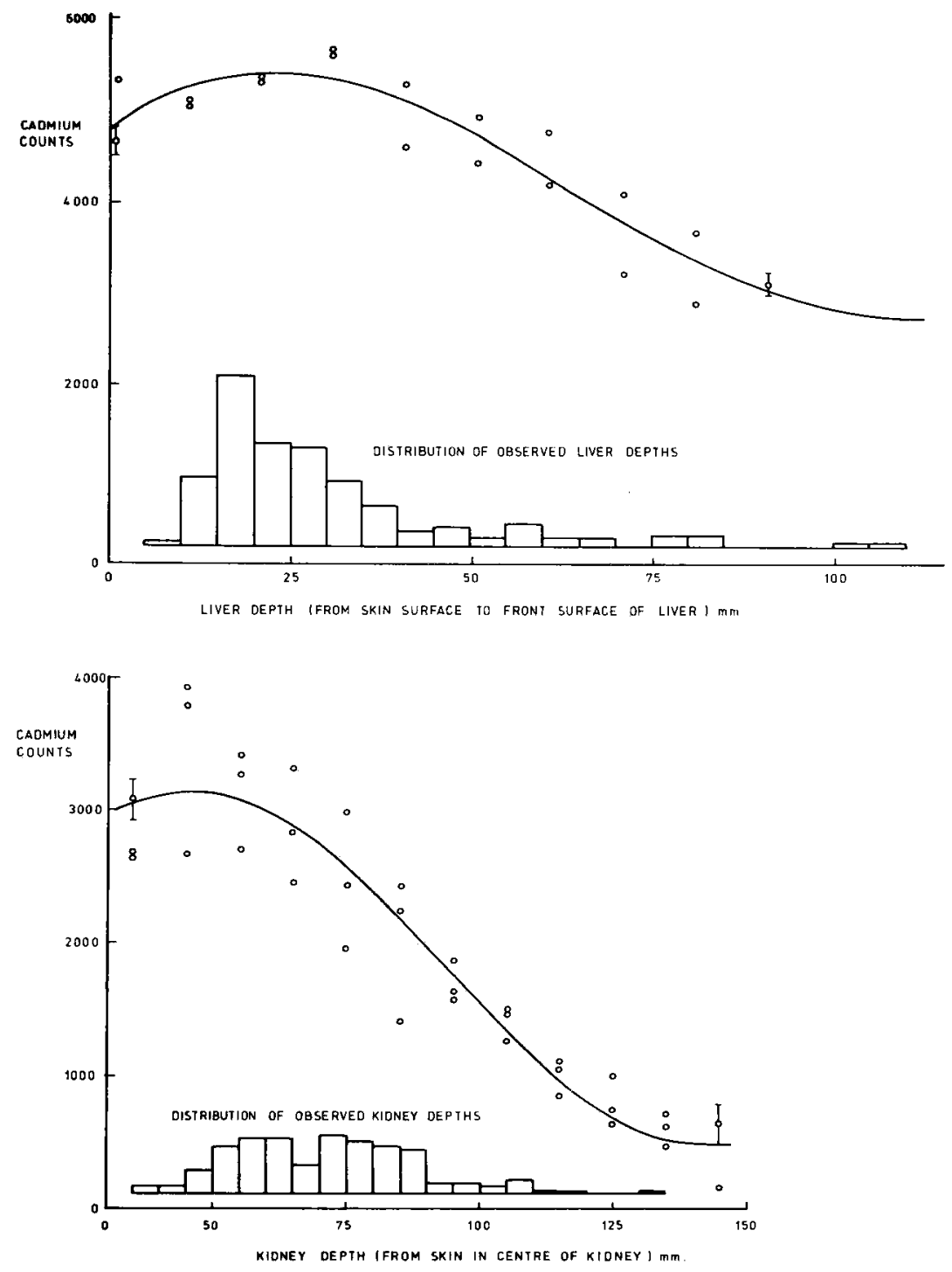

Figure 6. Variation in cadmium detection efficiency with organ depth for the liver (upper figure) and kidney (lower figure).

Measurement using $X$-ray fluorescence. Both because the average kidney depth is not too great and because the organ cadmium burden and concentration can be quite high, X-ray fluorescence has been used for in vivo analysis by Ahlgren \& Mattsson (3). For their first measurement they used an ${ }^{241} \mathrm{Am}\left({ }^{241}\right.$ americium) source, having a principle gamma-ray energy of $59.5 \mathrm{keV}$, to excite the cadmium, the $K_{\alpha} X$ rays, at $23.1 \mathrm{keV}$, being detected. The measurement system is shown in figure 7 , the source-organ-detector angle being $110^{\circ}$. At this angle the cadmium $K_{\alpha} X$ rays are well separated from the Compton scatter peak, at $\sim 52 \mathrm{keV}$, and occur at a local minimum in the gamma-ray background, as can be seen from figure 8 . The minimum detectable concentration is very dependent on the organ depth, in strong contrast to the case for neutrons. However, for an average organ dose of $0.6 \mathrm{mSv}(60 \mathrm{mrem})$, their sensitivity varied from $20 \mu \mathrm{g} \cdot \mathrm{g}^{-1}$ (for a 3-cm organ depth) to $40 \mu \mathrm{g} \cdot \mathrm{g}^{-1}$ (for a $4-\mathrm{cm}$ organ depth). The measurement sensitivity for a given organ dose is less for X-ray fluorescence than for neutron activation, although the sensitivity per whole-body dose equivalent may be greater, because of the different interaction characteristics of neutrons and photons. However, one important aspect of the $\mathrm{X}$-ray fluorescence technique is that it essentially measures the cadmium concentration in the kidney cortex. This is simply because of the rapid fall in sensitivity with tissue depth that arises both from changes in the solid angle and from the small attenuation mean-free paths for both the primary photons $(5.0 \mathrm{~cm})$ and, especially, the cadmium $X$ rays $(1.64 \mathrm{~cm})$. Thus a comparison between kidney cadmium measurements made with X-ray fluorescence and neutron activation analysis should allow the partition of cadmium between the cortex and medulla to be determined in vivo. 
Although, as we have noted, the peak of the Compton-scattered background is well separated from the $\mathrm{X}$-ray peaks of interest, there is, nevertheless, a Compton-scattered background under the X-ray peaks, and this background limits the measurement sensitivity. One way of reducing this problem is to use polarized $\mathrm{X}$ rays instead of gamma rays to induce $\mathrm{X}$-ray fluorescence. Putting the $\mathrm{X}$-ray detector at $90^{\circ} \mathrm{C}$ to the incident polarized $\mathrm{X}$-ray beam results in a very considerable reduction in the scattered background, and polarized X-rays can be produced quite simply by scattering unpolarized $\mathrm{X}$-rays from standard hospital machines through $90^{\circ}$, using a polymethylmethacrylate target. Such a technique has been applied to in vivo kidney cadmium measurement by Christoffersson \& Mattsson (14). For a fixed measurement time of $30 \mathrm{~min}$ they showed that, compared to the use of ${ }^{241} \mathrm{Am}$, the minimum detectable concentration fell from $20 \mu \mathrm{g} \cdot \mathrm{g}^{-1}$ to $8 \mu \mathrm{g} \cdot \mathrm{g}^{-1}$, ie, a factor of 2.5 . With this method, the organ dose increased, from 0.6 to $1.8 \mathrm{mSv}$ ( 60 to $180 \mathrm{mrem}$ ). However, were one to improve the sensitivity using ${ }^{241} \mathrm{Am}$ by increasing the organ dose to $1.8 \mathrm{mSv}$, the improved sensitivity would only be a factor of 1.7 , significantly less than that obtained using polarized $\mathrm{X}$ rays.

\section{Lead}

Because of the extremely small neutron cross sections of lead, X-ray fluorescence is the main technique for in vivo lead analysis, although nuclear resonance scattering of gamma rays, a technique which is discussed in another section, has been investigated (28). The main organ of accumulation for lead is bone (7), so that measurements have concentrated on bone sites, although there has been some interest in lead uptake in teeth, particularly in children (9).

The first bone lead measurements were made by Ahlgren et al (1) and Ahlgren \& Mattsson (2), who used a ${ }^{57} \mathrm{Co}\left({ }^{57}\right.$ cobalt) source and a $90^{\circ}$ detection geometry to measure lead in the finger bones of five occupationally exposed workers. A very similar configuration has been used by Price et al (41), and by Bloch \& Shapiro (10), who used it to measure lead in teeth. The same source and a $90^{\circ}$ detection geometry was also investigated by Laird et al (32) to measure lead in tibia. The ${ }^{57} \mathrm{Co}$ source emits gamma rays of $122 \mathrm{keV}(86 \%)$ and $136 \mathrm{keV}(11 \%)$, and a $90^{\circ}$ geometry puts the main Compton peak at $99 \mathrm{keV}$. This energy is significantly above the lead $K_{\alpha 1}$ and $K_{\alpha 2} X$-ray energies of 75.0 and $72.8 \mathrm{keV}$, respectively, but near the $\mathrm{K}_{\beta 1-3} \mathrm{X}$ rays, with energies of $85.0,87.3$, and $84.5 \mathrm{keV}$.

The $\mathrm{K}_{\alpha} \mathrm{X}$ rays were also measured by Somervaille et al $(50,51)$, but they used a ${ }^{109} \mathrm{Cd}$ source in an approximately backscatter $\left(153^{\circ}\right)$ geometry, in order to put the Compton peak from the $88.035 \mathrm{keV}$ gamma rays below the lead X-ray peaks. The advantage of using ${ }^{109} \mathrm{Cd}$ is that, because the gamma-ray energy is only just above the lead $\mathrm{K}$ edge (at $88.005 \mathrm{keV}$ ), the photoelectric cross section is highest and the X-ray fluorescence yield is maximized. In addition, the $\mathrm{K}$ $\mathrm{X}$-ray peaks are above the Compton scatter peak, leading to an improved signal to background ratio.

In contrast to these workers, Wielopolski et al (59, 60) used lower energy photon sources (either ${ }^{125}$ I ( ${ }^{125}$ iodine) or the silver $\mathrm{KX}$ rays from ${ }^{109} \mathrm{Cd}$ ) and $90^{\circ}$ geometry to measure tibia lead using the $\mathrm{L} X$ rays, with energies of $10.55 \mathrm{keV}\left(\mathrm{L}_{\alpha}\right)$ and $12.61 \mathrm{keV}\left(\mathrm{L}_{\beta}\right)$. A summary of the main features of each of these approaches is given in table 2 , and typical measurement geometries are illustrated in figures 9 and 10 . The latter shows the Birmingham configuration, which uses a 7.5 $\mathrm{GBq}(200 \mathrm{mCi})$ annular ${ }^{109} \mathrm{Cd}$ gamma-ray source (Amersham International, type CVC Q8206); the halflife is $470 \mathrm{~d}$ so that, in practice, the source can be used for about two years before counting times become excessive. The gamma-ray detector is an Ortec-planar hyperpure germanium having a diameter of $16 \mathrm{~mm}$ and a thickness of $7 \mathrm{~mm}$. It has the advantage of being cheaper than the larger coaxial detectors and of having

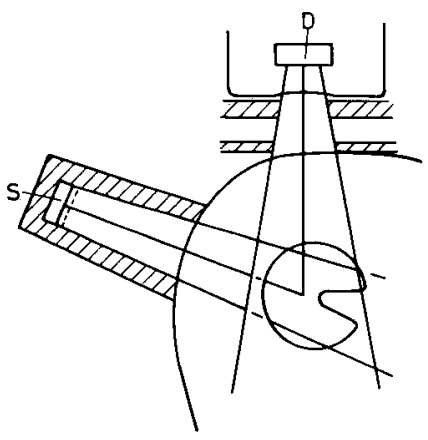

Figure 7. X-ray fluorescence measurement of cadmium in kidney (3). [ $S=$ source (241americium), D = detector (lithiumdrifted germanium)]

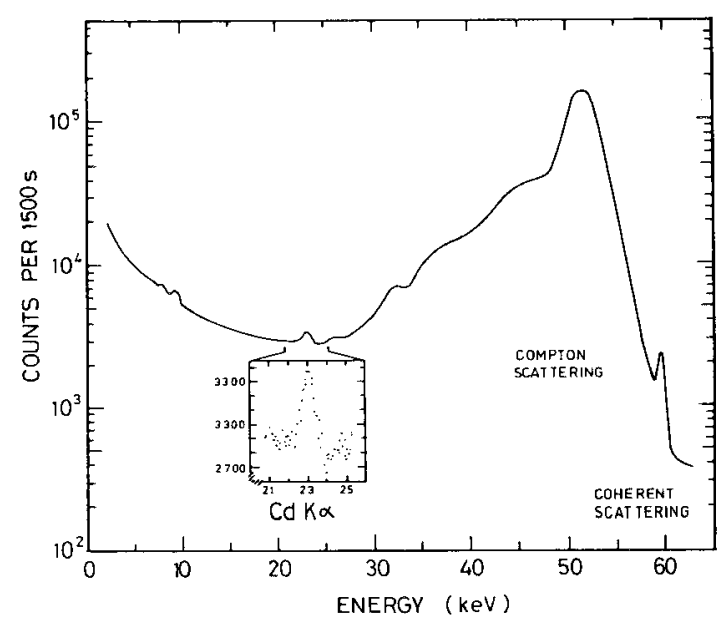

Figure 8. Cadmium (Cd) X-ray fluorescence spectrum (3). 
Table 2. Summary of the characteristics of systems measuring lead in bone. $(\mathrm{Cd}=$ cadmium, $\mathrm{Co}=$ cobalt, $1=$ iodine $)$

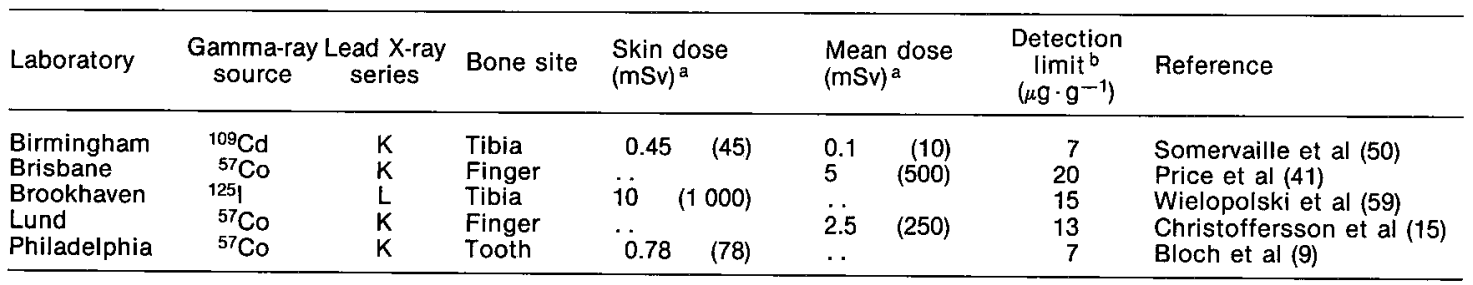

a The values in parentheses are the equivalent in mrem.

b Two times the standard deviation of the background.

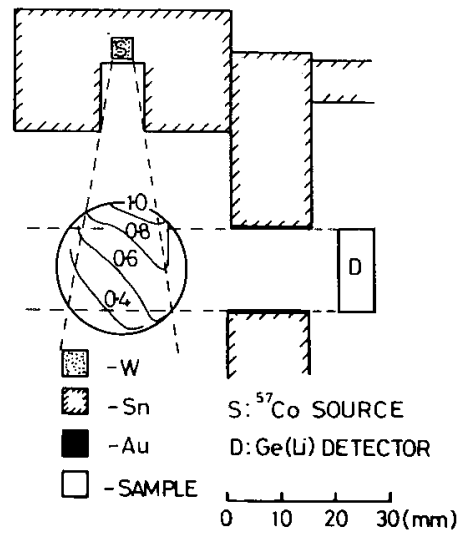

Figure 9. $X$-ray fluorescence measurement of lead in finger bone (2). (W = tungsten, $S n=$ tin, $A u=$ gold, $C o=$ cobalt, $\mathrm{Ge}=$ germanium, $\mathrm{Li}=$ lithium)

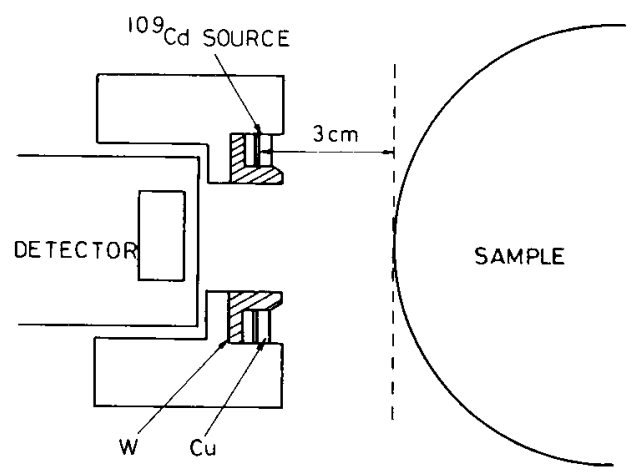

Figure 10. $X$-ray fluorescence measurement of lead in tibia, using ${ }^{109} \mathrm{Cd}$. ( $\mathrm{Cd}=$ cadmium, $\mathrm{W}=$ tungsten, $\mathrm{Cu}=$ copper)

better resolution, and these factors more than off-set any loss of detection efficiency. The tungsten collimator is made from a machinable alloy (GEC Ltd, United Kingdom), and the 0.5 -mm thick copper foil reduces the dose from the $25-\mathrm{keV}$ source $\mathrm{X}$ rays without significantly attenuating the $88-\mathrm{keV}$ gamma rays.

In order to relate the measured lead X-ray intensity to the average bone lead concentration, lead-doped bone phantoms are normally used, with a tissue-like overlay. However, we note that, with all the techniques, photon attenuation in the overlying tissue is
Table 3. Comparison of coherent cross sections for $88-\mathrm{keV}$ photons.

\begin{tabular}{|c|c|c|c|}
\hline Medium & $\begin{array}{c}\text { Cross section } \\
\left(\mathrm{cm}^{2} \cdot \mathrm{g}^{-1} \cdot \text { ste- }\right. \\
\left.\text { radian }^{-1}\right) \\
140^{\circ}\end{array}$ & $\begin{array}{c}\text { Cross section } \\
\left(\mathrm{cm}^{2} \cdot \mathrm{g}^{-1} \cdot \text { ste- }\right. \\
\left.\operatorname{radian}^{-1}\right) \\
153^{\circ}\end{array}$ & $\begin{array}{c}\text { Cross section } \\
\left(\mathrm{cm}^{2} \cdot \mathrm{g}^{-1} \cdot \text { ste- }\right. \\
\left.\text { radian-1) }^{-1}\right) \\
170^{\circ}\end{array}$ \\
\hline Soft tissue & $1.7 \cdot 10^{-6}$ & $1.5 \cdot 10^{-6}$ & $1.4 \cdot 10^{-6}$ \\
\hline Cortical bone & $43.3 \cdot 10^{-6}$ & $41.8 \cdot 10^{-6}$ & $41.0 \cdot 10^{-6}$ \\
\hline $\begin{array}{l}\text { Plaster of Paris } \\
\left(\mathrm{CaSO}_{4}, 2 \mathrm{H}_{2} \mathrm{O}\right)\end{array}$ & s $52.8 \cdot 10^{-6}$ & $50.8 \cdot 10^{-6}$ & $49.8 \cdot 10^{-6}$ \\
\hline $\begin{array}{l}\text { Paraffin wax } \\
(\mathrm{CH})\end{array}$ & $0.2 \cdot 10^{-6}$ & $0.2 \cdot 10^{-6}$ & $0.2 \cdot 10^{-6}$ \\
\hline Mix "D" wax & $3.9 \cdot 10^{-6}$ & $3.8 \cdot 10^{-6}$ & $3.7 \cdot 10^{-6}$ \\
\hline
\end{tabular}

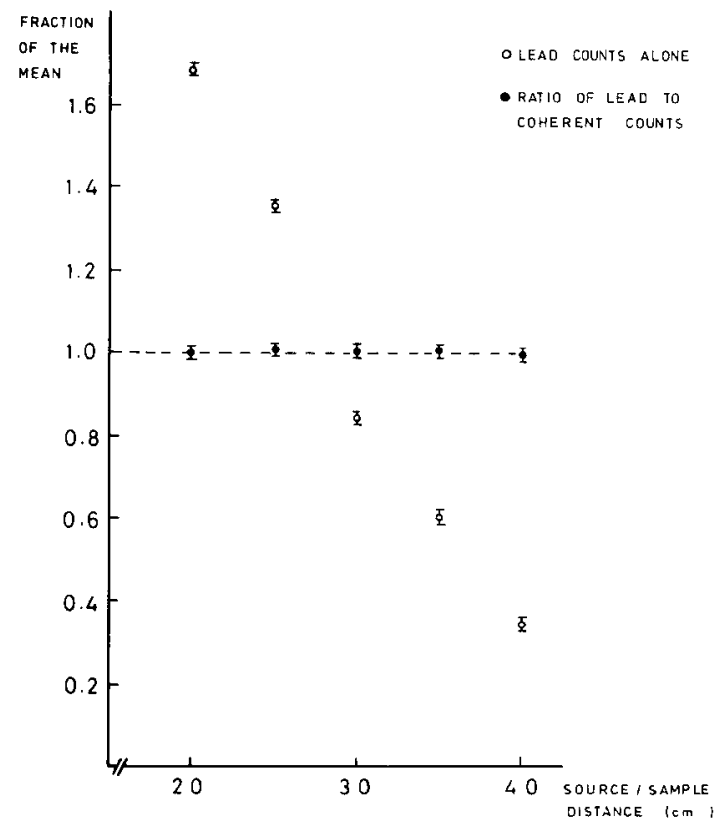

Figure 11. Effect of normalizing lead counts to coherent counts in minimizing uncertainties from variations in sourceto-sample distance.

very significant, and uncertainties about tissue thickness and source-subject geometry can introduce significant errors. To overcome this problem the sourcesubject geometry is normally tightly controlled, and the depth of overlying tissue is estimated by, for ex- 
ample, ultrasound (59) or by measurement of skinfold thickness (49). Clearly, accurate phantom modeling of the organ being measured can reduce all these uncertainties, an approach adopted by Ahlgren \& Mattsson (2), who also used the ratio of coherent to Compton scattering as an index of bone mineral content of the volume sampled.

The problems of relating lead X-ray intensity to bone mineral content can be overcome if a ${ }^{109} \mathrm{Cd}$ gammaray source is used, by normalizing the lead signals to the intensity of coherently (elastically) scattered gamma rays. The reasons for this are discussed in detail by Somervaille et al (50). Briefly, there are two reasons. The first is that the lead $\mathrm{K}$ edge is so near the source gamma-ray energy that both the lead X-ray peak and the coherent scatter intensities are proportional to the

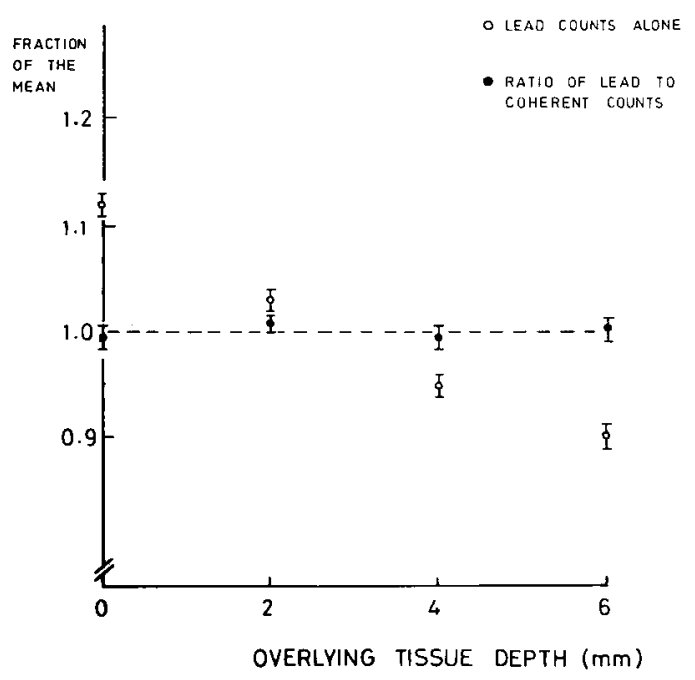

Figure 12. Effect of normalizing lead counts to coherent counts in minimizing uncertainties arising from variations in overlying tissue depth. uncollided incident gamma flux. The second reason is that the $\mathrm{Z}$ and angular dependence of the coherent scattering cross section means that the main contribution to the coherently scattered signal comes from medium-weight bone constituents (calcium and phosphorus) and that the overlying and surrounding tissue makes only a minor contribution. Values of the coherent-scattering cross section for tissue, bone, and some phantom materials are given in table 3 . That this normalization removes the two uncertainties concerned can be seen from figures 11 and 12 , while figure 13 shows a measured X-ray spectrum from a bone phantom with a lead level of $1000 \mu \mathrm{g} \cdot \mathrm{g}^{-1}$ to illustrate the main features of the response. In practice bone lead levels are much lower than this, and figure 14 shows a measured spectrum for a worker having a lead level of 83 (SD 7) $\mu \mathrm{g} \cdot \mathrm{g}^{-1}$ in (wet) bone. It can be seen from this figure that only the $\mathrm{K}_{\alpha 1}$ and $\mathrm{K}_{\alpha 2}$ lines are distinguishable above background, and a nonlinear least squares fitting program is used to extract the peak areas $(8,34)$.

The question of radiation dose is clearly an important aspect regarding the acceptibility of any radiation technique for routine monitoring or research. For all the X-ray fluorescence techniques discussed here, the doses are small, as can be seen from table 2 , and are only to a small section of the body. In addition, the bone sites chosen so far are a long way from any other critical organs and contain only a small proportion of the bone marrow.

In order to gain a complete picture of skeletal lead burden, and to establish any metabolic differences between, for example, cortical and trabecular bone, it is clearly desirable to make measurements on a number of bone sites. In principal, any of the $\mathrm{K}_{\alpha}$ methods could measure a range of bone sites, even those with overlying tissue or a complicated geometry (eg, vertebrae). However, the problem of relating measured $\mathrm{X}$-ray peak intensities to bone-lead concentration

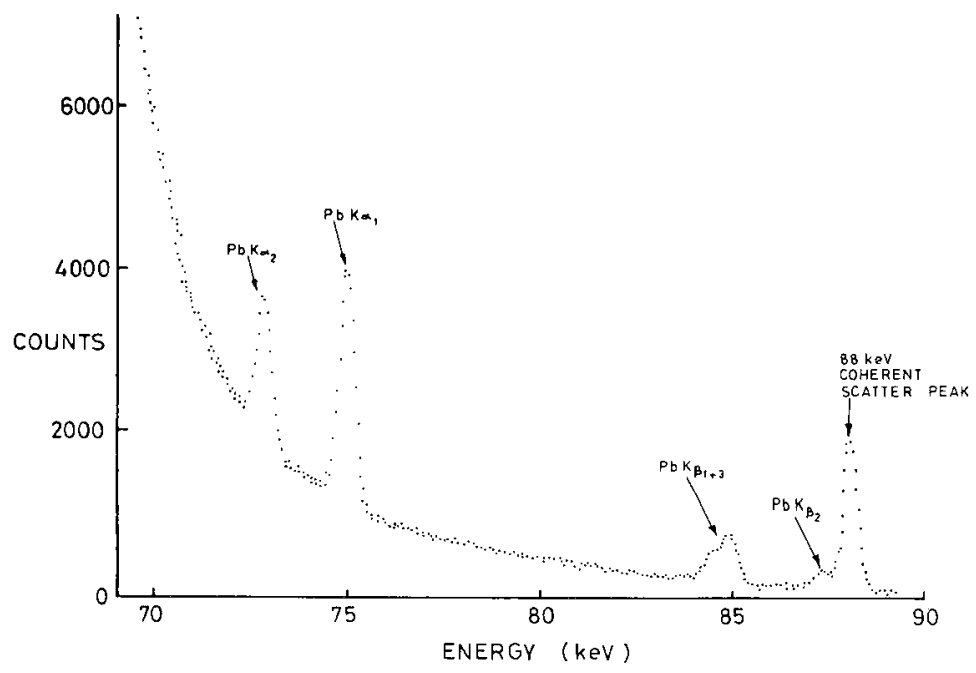

Figure 13. Lead $(\mathrm{Pb}) \mathrm{X}$-ray fluorescence spectrum, using ${ }^{109} \mathrm{Cd}$, from a bone phantom (1 $\left.000 \mu \mathrm{g} \cdot \mathrm{g}^{-1}\right)$. 


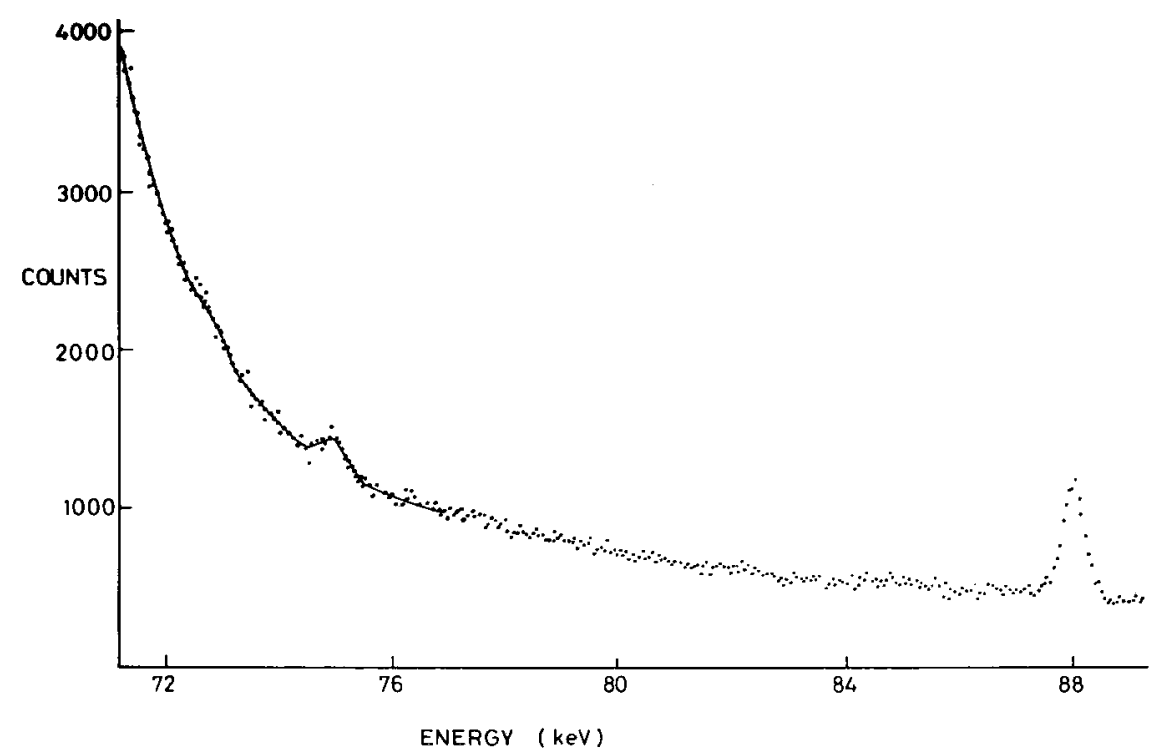

Figure 14. In vivo lead $X$-ray spectrum from a worker having a lead level of 83 (SD 7 ) $\mu \mathrm{g} \cdot \mathrm{g}^{-1}$ in tibia. favors the approach using ${ }^{109} \mathrm{Cd}$ with coherent-scatter normalization, since the bone phantoms used do not have to bear any geometrical resemblance to those measured. Using ${ }^{57} \mathrm{Co}$ it would be necessary to model the bone and overlying tissue geometry very carefully to avoid systematic errors. The only factor militating against the use of ${ }^{109} \mathrm{Cd}$ is that of cost.

\section{Applications to other elements and other experimental procedures}

Procedures involving neutrons. Although they have not yet been developed to the point where in vivo measurements have been made, nevertheless, for completeness, we mention two developments involving neutrons which could have significance for occupational health studies, namely, the measurement of silicon and beryllium.

In studying the possibility of measuring silicon in lungs, Ettinger et al (26) investigated the use of inelastic neutron scattering in ${ }^{28} \mathrm{Si}$ (92\% abundant), concentrating on the $1.799-\mathrm{MeV}$ gamma rays from the first excited state. They chose this method because of the low thermal neutron capture cross section of ${ }^{28} \mathrm{Si}(16$ mbarns) and because of gamma-ray interference from neutron interactions with other body elements. From their measurements, involving a number of different radioisotope and accelerator sources, they defined a system, based on a 6-MeV pulsed accelerator producing neutrons by the $\mathrm{D}(\mathrm{d}, \mathrm{n})$ reaction and using six $\mathrm{Ge}(\mathrm{Li})$ detectors, which should be capable of detecting $0.15 \mathrm{~g}$ of silicon in lungs for a dose of $0.01 \mathrm{~Sv}(1 \mathrm{rem})$. At lower doses the detection limits would be $0.2 \mathrm{~g}$ ( $5 \mathrm{mSv}, 500 \mathrm{mrem})$ or $0.3 \mathrm{~g}(2.5 \mathrm{~m} \mathrm{~Sv}, 250 \mathrm{mrem})$. They also observed that 14-MeV neutrons from a low-energy accelerator could be used as the source, although there would be a $30 \%$ reduction in sensitivity. These quantities are to be compared to an estimate of 0.19 to $0.33 \mathrm{~g}$ of silicon as free silica in the lungs of different classes of miners with early to moderate fibrosis.

Although not in widespread use, beryllium is of occupational health interest because of its extreme toxicity when inhaled. The possibility of measuring it in vivo using the ${ }^{9} \mathrm{Be}(\gamma, \mathrm{n})$ reaction has been investigated by Ettinger et al (25) and later by Ali et al (5). The principle of the method is that the subject is irradiated with gamma rays with energies above the ${ }^{9} \mathrm{Be}(\gamma, \mathrm{n})$ reaction threshold (at $1.67 \mathrm{Mev}$ ), but below that for the $\mathrm{D}(\gamma, \mathrm{n})$ reaction at $2.2 \mathrm{MeV}$, and any neutrons produced are slowed down in a graphite moderating assembly and detected as thermal neutrons in $\mathrm{BF}_{3}$ (boron trifluoride) counters. Extrapolating from phantom studies, Ali et al (5) estimated the whole-lung measurement sensitivity to be $0.67 \mathrm{mg}$ for a skin dose of $50 \mathrm{mSv}(5 \mathrm{rem})$ using a lead filtered ${ }^{125} \mathrm{Sb}-\mathrm{Be}\left({ }^{125} \mathrm{anti}\right.$ mony-beryllium) neutron source and an array of $20 \mathrm{BF}_{3}$ counters. To reduce background the measurement time proposed was only $90 \mathrm{~s}$.

Other neutron-based techniques which have been explored for in vivo analysis and which may be of interest in occupational medicine include the detection of lithium in brain (57), of mercury in the kidney (46, 47 ), and of whole-body silver (20).

Use of $X$-ray fluorescence. The X-ray fluorescence technique already described has been used, or proposed, for the investigation of a number of other elements. For example, Snyder \& Secord (48) have measured the strontium concentration in bone in rabbits and a dog, using the $22-$ and $25-\mathrm{keV}$ silver $\mathrm{X}$ rays from a ${ }^{109} \mathrm{Cd}$ source, the strontium $\mathrm{K}_{\alpha}$ and $\mathrm{K}_{\beta} \mathrm{X}$ rays 
being at 14.2 and $15.9 \mathrm{keV}$, respectively. Their measurement geometry was similar to that shown in figure 9 for lead measurements. They note that the very small half thickness for the strontium $X$ rays in bone $(0.44 \mathrm{~mm}$, corresponding to an attenuation mean free path of $0.63 \mathrm{~mm}$ ) means that only the surface $2 \mathrm{~mm}$ or so is sampled, and the presence of overlying tissue seriously limits sensitivity.

Because only relative measurements were made studying the time behavior of injected strontium Snyder \& Second (48) made no estimates of absolute sensitivity; the dose involved was $6 \mathrm{mSv}(600 \mathrm{mrem})$. However, Wielopolski et al (61) used both a ${ }^{109} \mathrm{Cd}$ and a ${ }^{125} \mathrm{I}$ source to measure strontium in human tibia. They reported a measurement sensitivity of $15 \mu \mathrm{g} \cdot \mathrm{g}^{-1}$ of wet bone for a radiation dose of $10 \mathrm{mSv}(1 \mathrm{rem})$ to a $1-\mathrm{cm}^{2}$ area of the tibia.

Because of their relatively high X-ray energies and high fluorescence yields, the heavy metals generally form a good subject for in vivo analysis with X-ray fluorescence, and Dutton et al (19) have investigated its use for platinum in kidney. They concluded that the lower limit of detection was $\sim 10 \mathrm{ppm}$, using multiple ${ }^{57} \mathrm{Co}$ sources, the skin dose being $12 \mathrm{mSv}(1.2$ rem). They also investigated the improvement in sensitivity which could be obtained using polarized $\mathrm{X}$-rays to stimulate X-ray emission and observed a factor-oftwo reduction in the background under the platinum $\mathrm{X}$-ray peaks. We note here the general point that the use of polarized $X$ rays has been proposed by a number of workers and for different elements in order to reduce the background under X-ray fluorescence peaks of interest, in the way described earlier.

The low concentrations involved make in vivo measurement of mercury in kidney difficult, and estimated sensitivities of $10 \mu \mathrm{g} \cdot \mathrm{g}^{-1}$ for radiation doses of $1.2 \mathrm{mSv}(0.12 \mathrm{rem})$ using X-ray fluorescence and $15 \mu \mathrm{g} \cdot \mathrm{g}^{-1}$ for a dose of $10 \mathrm{mSv}$ (1 rem) using 2-keV neutrons (47) are above the levels normally encountered in cases of mercury poisoning. However, Bloch \& Shapiro (10) used X-ray fluorescence to measure mercury in vivo in the wrists and temporal region of dentists, who are exposed to mercury because of its use in the amalgams used for filling. For a dose of $0.6 \mathrm{mSv}(60 \mathrm{mrem})$ they were able to detect a mercury level of $30 \mu \mathrm{g} \cdot \mathrm{g}^{-1}$ with a $90 \%$ confidence limit. In their study they used a ${ }^{57} \mathrm{Co}$ source to produce the 70.82 - and $68.89-\mathrm{keV}$ mercury $\mathrm{K}_{\alpha 1}$ and $\mathrm{K}_{\alpha 2} \mathrm{X}$ rays, in a geometry also similar to that in figure 10 .

Use of nuclear resonance scattering. A completely different technique, that of nuclear resonance scattering (NRS), has been used to measure a number of elements, including iron $(54,56)$ and copper $(52,55)$. The principle of the method is elegant and sounds deceptively simple. In practice, it is often very difficult to use. If nuclei are irradiated with photons (normally gamma rays), scattering resonances are observed, corresponding to excitation and deexcitation of the nuclear energy levels. These resonances are, however, extremely narrow ( $\sim 1 \mathrm{eV}$ at room temperature). Consequently, because of the small energy shift between the absorption and emission energies - arising from momentum conservation considerations - the overlap between the two is negligibly small under normal circumstances.

Thus the gamma rays from deexcitation of a nucleus following radioactive decay cannot be resonantly scattered from a nucleus of the same element unless the recoil energies following emission and absorption (typically $10 \mathrm{eV}$ each for the medium-weight elements) are compensated for. Such compensation can be obtained by a number of methods, which have been discussed by Metzger $(36,37)$. For example, if the radioisotope of interest decays by electron capture and the atom forms part of a larger molecule, then Coulomb fragmentation can occur. More specifically, following electron capture, multiple Auger electron emission results in a highly charged atom; this is followed by rapid redistribution of the charge to other atoms in the molecule, and the resulting Coulomb repulsion between the atoms splits the molecule. If gamma ray emission takes place while the recoil nuclei are still in motion (hence the importance of having the molecule in the gaseous phase), then its energy will be Doppler shifted. The net result is a broadening of the gamma emission lines.

The practical problems associated with this technique are beyond the scope of this review. We note, however, that it has been used for the in vivo analysis of iron in liver $(55,56)$, the radioactive source used being ${ }^{56} \mathrm{Mn}$ ( ${ }^{56}$ manganese) (half-life $=2.58 \mathrm{~h}$ ) as ${ }^{56} \mathrm{Mn} \mathrm{Cl}_{2}$ (manganese-56 chloride), heated to $1000^{\circ} \mathrm{C}$ or so. In this case, the necessary spectral shift of the emitted gamma rays is obtained from the nuclear recoil following beta-particle emission. About $1 \mathrm{Ci}$ $\left(3.7 \cdot 10^{10} \mathrm{~Bq}\right)$ of ${ }^{56} \mathrm{Mn}$ was used, the $847-\mathrm{keV}$ iron gamma line being measured with two hyperpure germanium detectors. The dose to the skin was $10 \mathrm{mSv}$ (1 rem), and the technique has been used to measure liver iron concentrations ranging from 1.3 (SD 2.1) to 19.8 (SD 3.1) $\mathrm{mg} \cdot \mathrm{g}^{-1}(58)$, the detection limit being quoted as $1 \mathrm{mg} / \mathrm{g}$ of wet tissue. A similar technique has been used by the same workers to measure iron in the heart.

As far as copper is concerned, we are not aware of any in vivo measurements, although Vartsky et al (55) and Thomas et al (52) have discussed the use of ${ }^{65} \mathrm{ZnI}_{2}$ (zinc-65 iodide) in conjunction with large $\mathrm{NaI}(\mathrm{Tl})$ (thallium-activated sodium iodide) scintillation counters to measure the 1.12-Mev gamma rays, and have estimated a lower limit of detection for copper in liver of $0.13 \mathrm{~g} \cdot \mathrm{rem}^{-1}$.

A summary of the elements which have been measured in vivo, and of the measurement techniques used, is given in table 4 . 
Table 4. Elements of interest in occupational medicine for which in vivo techniques have been developed.

\begin{tabular}{lll}
\hline Element & Method of measurement & References \\
\hline Cadmium & Neutron activation (prompt) & $4,12,18,22$, \\
& & $31,35,39,40$ \\
Lead & X-ray fluorescence & 3,14 \\
& X-ray fluorescence & $1,2,9,32,41$, \\
& & $49,50,51,59$, \\
Mercury & X-ray fluorescence & 60 \\
& Neutron activation (prompt) & $10,45,46,47$ \\
Strontium & X-ray fluorescence & $45,46,47$ \\
Platinium & X-ray fluorescence & 48,61 \\
Beryllium & Photo-nuclear (prompt) & 19 \\
Silicon & Neutron scattering & 5,25 \\
Copper & Neutron activation (delayed) & 6,26 \\
& Gamma-ray resonance fluorescence & 52,55 \\
Iron & Neutron activation (delayed) & 6 \\
& Gamma-ray resonance fluorescence & 54,56 \\
Silver & Neutron activation (delayed) & 20 \\
Lithium & Neutron activation (delayed) & 57 \\
\hline
\end{tabular}

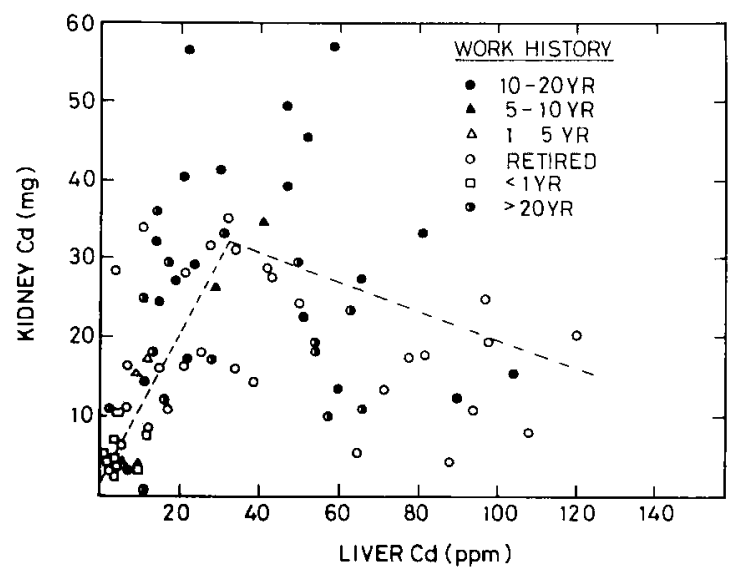

Figure 15. Relationship of kidney cadmium (Cd) to liver cadmium in an industrially exposed population (21). (YR = year)

\section{Clinical interpretation of in vivo data}

\section{Introduction}

With the exception of cadmium, and possibly lead, the techniques reported here have so far been restricted to studies involving relatively few subjects, so that detailed analyses of the relationship between the results of in vivo analysis and general health status have not been attempted. In the case of lead, a number of in vivo bone lead measurements have been made, including those by Price et al (41), Christoffersson et al (15), and Somervaille et al (50). Nevertheless, the breadth of the related effects studied is still small, although detailed studies involving large numbers of workers are in progress in our own group, and are certainly in progress elsewhere.

In contrast, in vivo measurement of cadmium in liver and kidney has been practiced for ten years or so, these being the principle organs of cadmium accumulation and accounting for approximately $50 \%$ of the cadmium body burden. There has been considerable discussion of the significance of the results, both in the literature and at conferences. For these reasons, we have chosen to discuss cadmium measurements only in this section, in order to illustrate the information and insight which in vivo analysis can afford.

\section{General considerations}

Cadmium is a relatively heavy metal with widespread use in industry. For example, it is used in pigments and as an accelerator in plastics, as one of the electrodes in nickel-cadmium batteries, as an alloying element in electrical conductors exposed to heavy wear (as in overhead electrical conductors for trains), as a constituent in brazing alloys, and as a corrosionresistant plating material. With such a wide range of uses, occupational exposure patterns clearly vary widely.

Because of its importance and known toxicity, its effects have been widely studied, and a comprehensive review of these effects is given in reference 27. Although inhalation of cadmium dust and fumes has, for example, been associated with emphysema, any correlation between this disease and liver and kidney cadmium burdens has still not been established, although it is currently actively being investigated. ${ }^{2}$ The main emphasis in the interpretion has therefore been on establishing the relationship between cadmium levels and renal dysfunction, with a related interest in which, if any, of the biochemical parameters measured in blood and urine analyses can be used to monitor worker health status.

\section{Biochemical parameters and in vivo measurements}

As far as the accumulation of cadmium in kidney and liver is concerned, it is clear from in vivo analyses that there is a distinct difference in the behavior of the two organs. Although excretion rates from liver may change with organ burden, such changes are not well established. Thus, in general terms, liver burden increases with exposure and, in many analyses, has, indeed, been used as an index of exposure.

In contrast, it has been shown quite unambiguously that cadmium levels in kidney exhibit a biphasic relationship. Kidney cadmium levels rise with exposure until the onset of kidney damage is accompanied by enhanced cadmium excretion, at which point there is a reduction in kidney cadmium. This relationship is illustrated in figure 15, and from these data Ellis et al (21) found the change in kidney cadmium uptake to occur at 31 (SD 9) $\mathrm{mg}$, a value corresponding to a cadmium liver level of about $35 \mu \mathrm{g} \cdot \mathrm{g}^{-1}$. The equiva-

\footnotetext{
2 In a collaborative program, initiated by the Brompton Hospital, London, and involving the Health and Safety Executive of the United Kingdom and ourselves.
} 
lent figures obtained by our own group from analysis of data from surveys made in the United Kingdom were $23 \mathrm{mg}$ in the kidney, with a liver level of 47 (SD 6) $\mu \mathrm{g} \cdot \mathrm{g}^{-1}(11,44)$.

Although, as we shall see, many symptoms of renal dysfunction are nonspecific to cadmium, cadmium in blood and urine can only come from cadmium exposure. The question of how each relates to cadmium exposure, uptake, and toxicological effects is therefore of considerable interest, both from the occupational health monitoring and metabolic modeling point of view. Lauwerys et al (33) measured the blood cadmium levels for four new cadmium workers for their first $150 \mathrm{~d}$ and found that they increased linearly up to $120 \mathrm{~d}$ and then leveled off. The leveling off point was postulated to be related to pollution level, and therefore to vary between work sites and occupations. It follows from this that blood cadmium levels are related to, and are therefore indices of, exposure over a period of months or so. It also follows that one would not expect a strong correlation between cadmium in blood and in kidney, and this assumption was confirmed by Lauwerys et al (33), who found a correlation coefficient $(r)$ of only $0.25(p<0.05)$ for 72 workers showing no signs of kidney dysfunction.

In contrast, urinary cadmium levels are related to kidney function, and their relationship to exposure and body burden therefore changes with time. On the basis of a survey of 11 workers over a period of a year, Lauwerys et al (33) proposed that, for workers with unsaturated cadmium binding sites, urinary cadmium levels are related to kidney, and hence body, burden. When such binding sites become saturated, corresponding to a urinary cadmium level of around $15 \mu \mathrm{g} / \mathrm{g}$ of creatinine, urinary cadmium excretion increases sharply, and the levels then relate to both body burden and recent exposure. They therefore identified the onset of renal dysfunction to correspond to urinary cadmium levels of between 10 and $20 \mu \mathrm{g} / \mathrm{g}$ of creatinine.

$\beta_{2}$-microglobulin is a medium-weight protein (molecular weight 11800 ) whose enhanced excretion rate in urine is accepted as a sensitive indicator of renal dysfunction. The increased excretion rate can arise from a reduced glomerular filtration rate, but it is most strongly dependent on tubular damage. Unfortunately, increased urinary $\beta_{2}$-microglobulin levels can arise from a wide variety of disease states, and are therefore not cadmium-specific (30). Nevertheless, measurement of urinary $\beta_{2}$-microglobulin, together with total protein and albumin levels, is normally made in association with determination of kidney and liver cadmium levels.

In a study of 82 occupationally exposed male workers and 10 controls, Ellis et al (21) showed that for those with normal kidney function (defined as having $\beta_{2}$-microglobulin levels of less than $200 \mu \mathrm{g} / \mathrm{g}$ of creatinine and urinary total protein levels of less than 250 $\mu \mathrm{g} / \mathrm{g}$ of creatine) the cumulative frequency distribu- tion showed $90 \%$ to have kidney cadmium burdens of less than $39 \mathrm{mg}$ (with $41 \mathrm{mg}$ for the 95 th percentile). The corresponding liver levels were $59 \mu \mathrm{g} \cdot \mathrm{g}^{-1}(90 \%)$ and $72 \mu \mathrm{g} \cdot \mathrm{g}^{-1}(95 \%)$. They also found that, for those with abnormal kidney function, the 90th and 95th percentile kidney cadmium levels were slightly lower than for the normals, a finding consistent with loss of kidney cadmium following renal damage. On the other hand, the corresponding liver levels were 98 and $106 \mu \mathrm{g} \cdot \mathrm{g}^{-1}$, ie, much higher than for normals.

Before giving further estimates of cadmium levels at which renal dysfunction occurs, we should discuss briefly the concept of "critical concentrations" in the kidney cortex. On the basis of post-mortem analyses, it has been established that kidney cadmium is more concentrated in the cortex than in the medulla, and a value of 1.5 for the ratio of cadmium concentration in the cortex to that in the whole kidney is commonly assumed (42). If the total organ content is known from in vivo analysis, the cortical concentration can therefore be estimated if the kidney weight is known or assumed; an average value of $145 \mathrm{~g}$ is widely used (42). We have noted earlier that, at least for kidneys which are not too deep, the cortical cadmium concentration can be measured directly using X-ray fluorescence (3, 14), but that so far most of the kidney data has been acquired using neutron activation analysis.

It follows from this that, if the kidney cadmium level (either whole organ or cortical concentration) for a particular change in body function (normally renal) is identified, the corresponding critical cortex concentration (expressed as micrograms of cadmium per gram of cortex) can be determined. However, the way in which the change in function is specified is clearly important. For example one could specify the response level below which 90 (or 95) \% of a normal population falls on a cumulative probability distribution; or one could specify the kidney cadmium level below which the phenomenon concerned does not occur; or one can use a mathematical model to determine the point at which a change in function occurs. Since these descriptions of a critical point differ, so too will the derived critical cortex levels, the degree of difference depending on the definitions used.

Assuming the kidney weights and cadmium distributions cited earlier, Ellis et al $(21,24)$ estimated a number of critical levels. Their critical renal cortex cadmium concentrations ranged from $312 \mathrm{ppm}$ (from the variation of kidney cadmium with years of exposure) to $413 \mathrm{ppm}$, corresponding to the level for the 90-95 percentile on the cumulative probability distribution for people with no renal dysfunction (as defined earlier). Their critical value for change in the urinary $\beta_{2}$-microglobulin level was $336 \mathrm{ppm}$.

As we have seen earlier, in vivo estimates of kidney and liver cadmium require knowledge of organ depth. However, in an early Belgian survey (42) no measurement of organ depth was made, a mean kidney depth of $5 \mathrm{~cm}$ being assumed. More recently, however, Roels 
et al (43) measured the organ depths of the workers concerned using ultrasound and recalculated the kidney burdens allowing for differences between workers. These measurements showed the range of kidney depths to be from 5.1 to $12.4 \mathrm{~cm}$, with a mean of 8.1 $\mathrm{cm}$, the mean kidney cadmium estimates increasing accordingly. Using this revised data, Roels et al defined the critical cortex level to be that below which no signs of kidney dysfunction appear and found it to be $216 \mu \mathrm{g} \cdot \mathrm{g}^{-1}$. The corresponding liver level was 30 $\mu \mathrm{g} \cdot \mathrm{g}^{-1}$, and the relationship between the liver and kidney cadmium for those with no kidney dysfunction was found, by measurement, to be

$$
\text { Cd (kidney) } \mathrm{ppm}=150+219 \mathrm{Cd} \text { (liver) } \mu \mathrm{g} \cdot \mathrm{g}^{-1} \text {. }
$$

We note, however, that this definition is more stringent than that used by Ellis et al, and so we would expect it to give a lower value for the critical concentration.

The possibility of a biphasic relationship existing between urinary protein levels and liver cadmium has been examined by Chettle et al (11) using a "broken stick" model. It was found that, for total protein and $\beta_{2}$-microglobulin in urine, a change in kidney function occurred at liver levels of 19 (SD 7) and 22 (SD 4) $\mu \mathrm{g} \cdot \mathrm{g}^{-1}$, respectively, whereas the corresponding point for change in the kidney cadmium level was 47 (SD 6) $\mu \mathrm{g} \cdot \mathrm{g}^{-1}$, as noted earlier. This finding raises the possibility that the two changes in function are unrelated. It also gives different critical cortex levels, which are, according to the standard assumptions given earlier, $140 \mu \mathrm{g} \cdot \mathrm{g}^{-1}$ for the change in protein excretion and $240 \mu \mathrm{g} \cdot \mathrm{g}^{-1}$ for loss of renal cadmium.

The question of whether or not there is any latency period for the onset of renal dysfunction was raised by Gompertz et al (29), who looked at a wide range of biochemical parameters, including urinary enzymes and relative clearance rates, in a study of 37 cadmium smelters. They identified a group of six workers who had only been exposed to cadmium for a relatively short time (mean 4.6 years), who had liver levels well above that at which kidney dysfunction could be expected (mean value $70 \mu \mathrm{g} \cdot \mathrm{g}^{-1}$ ), yet who showed no signs of renal dysfunction. Their mean renal cadmium level was $19.3 \mathrm{mg}$. This apparent anomaly raised the question of whether or not these workers would be subject to renal dysfunction without further cadmium exposure, assuming a continued kidney build-up by transport from the liver. The resulting time delay would then correspond to a latency period.

We turn, now, to some other aspects of cadmium exposure. The first concerns the possibility of a link between cadmium body burden and hypertension. Morgan et al (38) measured the kidney cadmium levels of 30 nonoccupationally exposed hypertensive subjects and 30 controls, matched for age, sex and smoking habits, and found that the means for the two groups were the same within experimental errors [3.3 (SD 2.3) $\mathrm{mg}$ and 4.4 (SD 2.7) $\mathrm{mg}$ for the hypertensives and con- trols, respectively]. However, when the comparison was made between matched pairs, the hypertensives had less kidney cadmium than the controls. The authors conjectured that this phenomenon could have been due to a loss of cadmium associated with treatment for hypertension. They also noted the well-known association between cigarette smoking and raised kidney cadmium levels, and estimated the increase to be $0.04 \mathrm{mg}$ per pack-year ( 20 cigarettes per day for a year). This level is of the same order as the value of $0.07 \mathrm{mg}$ per pack-year obtained using the data of Ellis et al (23).

We have already noted that raised $\beta_{2}$-microglobulin excretion is not specific to cadmium-induced renal dysfunction, and for monitoring cadmium workers it is clearly desirable to have a biochemical function which is cadmium-related. The use of metallothionein has been explored by Tohyama et al (53), who measured liver and kidney cadmium levels in a group of 16 cadmium smelters and 14 controls, as well as urinary $\beta_{2}$-microglobulin and metallothionein levels. They found that, whereas there was no significant difference in the mean $\beta_{2}$-microglobulin levels between the two groups (which were further subdivided according to previous work history), there was a distinct difference between their metallothionein levels. These differences were related to liver cadmium levels although, because of changes in renal function, the correlation with renal burden only existed before the onset of renal dysfunction.

\section{Current status of in vivo analysis in occupational health}

Although, as we have seen, a large number of in vivo techniques have been developed, and applied to a range of elements, the techniques used are fairly esoteric and require specialized facilities not often found in the hospital context. However, much of the equipment can be made portable so that occupational health surveys can be made at factory sites. From the point of view of disruption of work schedules - often an important feature in the acceptibility of a monitoring program - such portable systems are therefore clearly advantageous.

Inasmuch as in vivo analysis allows measurement of the organ, or body, burden of an element of interest, it can clearly play an important role in the understanding of elemental metabolism and related health effects. As such, in vivo analysis can be important in relation to occupational exposure criteria. For example, we have discussed the fact that some biochemical parameters of bodily function are not specific to a single toxic element. We have also seen that some biochemical indicators are indicative of recent exposure, whereas others are related to body burden. In all these cases, in vivo analysis can assist in delineating the different parts of the problem. 
So far, the application of the in vivo analysis to occupational health has been limited to research programs. However, as the techniques and the understanding of them are refined, it is possible that such measurements may be adopted for routine monitoring and/or screening, particularly where radiation doses are low, as in the case of bone lead measurements. Such an approach has to be seen against a background of national and international laws relating to occupational exposure, which have succeeded, quite dramatically in many cases, in improving occupational health. Thus, one could argue, for example, that the need for regular blood checks on lead workers is less important than it was and that cumulative body burden measured, say, every five years would be a simpler and adequate means of monitoring occupational exposure.

As the body of data relating to the uptake of a particular element grows, so too does the ability to make predictive comments relating to individuals, and this can clearly be of value in occupational medicine. In general, however, it is likely that the role of in vivo analysis will remain that of promoting an understanding of elemental uptake and effects, and that this will be its principle contribution to the occupational health field.

\section{Acknowledgments}

The authors' participation in research on in vivo activation analysis has been possible because of support for different programs from a number of organizations, including the Medical Research Council, London, the Health and Safety Executive of the United Kingdom, and the International Lead Zinc Research Organisation, to all of whom we wish to express our gratitude.

\section{References}

1. Ahlgren $K$, Lidén $K$, Mattsson $S$, Tejning S. X-ray fluorescence analysis of lead in human skeleton in vivo. Scand J Work Environ Health 2 (1976) 82-86.

2. Ahlgren L, Mattsson S. An X-ray fluorescence.technique for in vivo determination of lead concentration in a bone matrix. Phys Med Biol 24 (1979) 136-145.

3. Ahlgren $\mathbf{L}$, Mattsson S. Cadmium in man measured in vivo by X-ray fluorescence analysis. Phys Med Biol 26 (1981) 19-26.

4. Al-Hiti K, Slaibi S, Al-Kayat T. Portable system for detecting cadmium in the human liver. Int J Appl Radiat Isot 30 (1979) 55-60.

5. Ali PA, Dutton J, Evans CJ, Morgan WD, Sivyer A. A feasibility study for the in-vivo measurement of beryllium by photonuclear activation. Phys Med Biol 20 (1985) 1277-1287.

6. Al-Tikrity SA. Partial body measurements of copper and iron by in-vivo neutron activation analysis. University of Birmingham, Birmingham England 1976. (Doctoral dissertation).

7. Barry PSI. Comparison of concentrations of lead in human tissues. $\mathrm{Br} J$ Ind Med 32 (1975) 119-139.

8. Bevington PR. Data reduction and error analysis for the physical sciences. McGraw-Hill Book Company, New York, NY 1969.

9. Bloch P, Garavaglia G, Mitchell G, Shapiro IM. Measurement of lead content of children's teeth in situ by X-ray fluorescence. Phys Med Biol 22 (1977) 56-63.

10. Bloch $P$, Shapiro IM. An X-ray fluorescence technique to measure the mercury burden of dentists in-vivo. Med Phys 8 (1981) 308-311.

11. Chettle DR, Coward S, Faddy MJ, Fletcher JG, Scott MC, Mason HJ, Smith NJ, Topping MD. Cadmium renal effect levels estimated from analysis of liver and kidney concentrations. In: Wilson D, Volpe RA, ed. Proceedings 4th international cadmium conferences, Munich 1983. Cadmium Association, London 1984, pp 172174.

12. Chettle DR, Franklin DM, Guthrie CJG, Scott MC, Somervaille LJ. In-vivo and in-vitro measurements of lead and cadmium. Biol Trace Elem Res (in press).

13. Chettle DR, Fremlin JH. Techniques of in-vivo neutron activation analysis. Phys Med Biol 29 (1984) 1011-1043.

14. Christoffersson JO, Mattsson S. Polarized X-rays in XRF analysis for improved in-vivo detectability of cadmium in man. Phys Med Biol 28 (1983) 1135-1144.

15. Christoffersson JO, Schutz A, Ahlgren L, Haeger Aronsen B, Mattsson S, Skerfving S. Lead in finger bone analysed in-vivo in active and retired lead workers. Am J Ind Med 6 (1984) 447-457.

16. Cierjacks $S$, ed. Neutron sources for basic physics and applications. Pergamon Press, Oxford 1983.

17. Cohn SH. The present state of in-vivo neutron activation analysis in clinical diagnosis and therapy. At Energy Rev 18 (1980) 599-660.

18. Cummins PE, Dutton J, Evans CJ, Morgan WD, Sivyer A. A sensitive ${ }^{252} \mathrm{Cf}$ neutron activation analysis instrument for in-vivo measurement of organ cadmium. J Radioanal Chem 71 (1982) 561-571.

19. Dutton J, Evans CJ, Samat SB, Morgan WD, Sivyer A. Feasibility studies of X-ray fluorescence as a method for the in-vivo determination of platinum and other heavy metals. Adv X-ray Anal 28 (1985) 145-154.

20. East BW, Boddy K, Williams ED, MacIntyre D, McLay ALC. Silver retention, total body silver and tissue silver concentrations in argyria associated with exposure to an anti-smoking remedy containing silver acetate. Clin Exp Dermatol 5 (1980) 305-311.

21. Ellis KJ, Morgan WD, Zanzi I, Yasumura S, Vartsky D, Cohn SH. Critical concentrations of cadmium in human renal cortex: Dose-effect studies in cadmium smelter workers. J Toxicol Environ Health 7 (1981) 691-703.

22. Ellis KJ, Vartsky D, Cohn SH. In-vivo monitoring of heavy metals in man: Cadmium and mercury. Neurotoxicology 4 (1983) 164-168.

23. Ellis KJ, Vartsky D, Zanzi I, Cohn SH, Yasumura S. Cadmium: In-vivo measurement in smokers and nonsmokers. Science 205 (1979) 323-325.

24. Ellis KJ, Yuen K, Yasumura S, Cohn SH. Dose-response analysis of cadmium in man: Body burden vs kidney dysfunction. Environ Res 33 (1984) 216-226.

25. Ettinger KV, Morgan WD, Miola U, Vartsky D, Ellis KJ, Wielopolski L, Cohn SH. A feasibility study for the in-vivo measurement of silicon and beryllium by nuclear techniques. In: US Department of Energy. 4th international conference on nuclear methods in environmental and energy research, Columbia, Miss. Washington, DC 1980, p 398. (CONF 800433).

26. Ettinger KV, Morgan WD, Miola UJ, Vartsky D, Ellis KJ, Wielopolski L, Cohn SH. Silicon measurement in a lung phantom by neutron inelastic scattering. Med Phys 9 (1982) 550-558.

27. Felder RJ, Dale EA. Toxicity review 7: Cadmium and its compounds. UK Health and Safety Executive, London 1983.

28. Fletcher JG. An investigation of nuclear resonance 
fluorescence of the elements iron and lead. University of Birmingham, Department of Physics, Birmingham England 1977. (MSc project report).

29. Gompertz D, Chettle DR, Fletcher JG, Mason H, Perkins J, Scott MC, Smith NJ, Topping MD, Blindt M. Renal dysfunction in cadmium smelters: Relation to in-vivo liver and kidney cadmium concentrations. Lancet 1 (1983) 1185-1187.

30. Kazantzis G. Significance of $\beta_{2}$ microglobulin as a measure of cadmium exposure: In: Cadmium Association. Occupational exposure to cadmium. London 1980, pp $55-56$.

31. Krauel JB, Speed MA, Thomas BW, Baddeley H, Thomas BJ. The in-vivo measurement of organ tissue levels of cadmium. Int J Appl Radiat Isot 3 (1980) $101-106$.

32. Laird EE, Chettle DR, Scott MC. The factors affecting in-vivo X-ray fluorescence measurements of lead in bone. Nucl Instrum Methods 193 (1982) 377-382.

33. Lauwerys R, Buchet JP, Roels H, Bernard A, Chettle DR, Harvey TC, Al-Haddad IK. Biological significance of cadmium concentration in blood and urine and their application in monitoring workers exposed to cadmium. In: Proceedings of the 2 nd international cadmium conference, Cannes, 1979. [Special volume of the Metal Bulletin (London) (1980) 164-167].

34. Marquardt DW. An algorithm for least-squares estimation of non linear parameters. J Soc Ind Appl Math 11 (1963) $431-441$.

35. McNeill KG, McLellan JS, Mohammad Amin AK, Vohra K, Mernagh JR. Measurement of cadmium invivo industrial workers. J Radioanal Chem 71 (1982) $573-580$.

36. Metzger FR. Resonance fluorescence in nuclei. Prog Nucl Phys 7 (1959) 53-88.

37. Metzger FR. Coulomb fragmentation of molecules, observed via the resonant scattering of gamma rays. Phys Rev Lett 18 (1967) 434-435.

38. Morgan WD, Cummins PE, Elwood PC, Evans CJ, Dutton J, Sivyer A. In-vivo neutron activation analysis in a study of cadmium and hypertension in South Wales. In: US Department of Energy. 4th international conference on nuclear methods in environmental and energy research, Columbia, Miss. Washington, DC 1980, pp 449-458. (CONF 800433).

39. Morgan WD, Ellis EJ, Vartsky D, Yasumura S, Cohn $\mathrm{SH}$. Calibration of a ${ }^{238} \mathrm{Pu}, \mathrm{Be}$ facility for partial-body measurements of organ cadmium. Phys Med Biol 26 (1981) 577-590.

40. Morgan WD, Vartsky D, Ellis KJ, Cohn SH. A comparison of ${ }^{252} \mathrm{Cf}$ and ${ }^{238} \mathrm{Pu}, \mathrm{Be}$ neutron sources for partial-body in-vivo activation analysis. Phys Med Biol 26 (1981) 413-424.

41. Price J, Baddeley H, Kenardy JA, Thomas BJ, Thomas BW. In-vivo X-ray fluorescence estimation of bone lead concentrations in Queensland adults. $\mathrm{Br} \mathrm{J}$ Radiol 57 (1984) 29-33.

42. Roels HA, Lauwerys RR, Buchet JP, Bernard A, Chettle DR, Harvey TC, Al-Haddad IK. In-vivo measurement of liver and kidney cadmium in workers exposed to this metal: Its significance with respect to cadmium in blood and urine. Environ Res 26 (1981) 217-240.

43. Roels H, Lauwerys R, Dardenne AN. The critical level of cadmium in human renal cortex: A re-evaluation. Toxicol Lett 15 (1983) $357-360$.

44. Scott MC, Chettle DR, Coward SA, Faddy MJ, Fletcher JG. Developments in in-vivo analysis of cadmium in liver and kidney. Trans Am Nucl Soc 44 (1983) $33-34$.

45. Smith JRH. The in-vivo measurement of mercury in human kidneys. University of Birmingham, Birmingham England 1983. (Doctoral dissertation).

46. Smith JRH, Athwal SS, Chettle DR, Scott MC. On the in-vivo measurement of mercury using neutron capture and X-ray fluorescence. Int J Appl Radiat Isot 33 (1982) $557-561$.

47. Smith JRH, Chettle DR, Scott MC. Methods for in-vivo measurement of mercury in human kidneys. In: CEP Consultants. International conference on heavy metals in the environment, Heidelberg 1983. Edinburgh 1983, pp 199-203.

48. Snyder RE, Secord DC. The in situ measurement of strontium content in bone using X-ray fluorescence analysis. Phys Med Biol 27 (1982) 515-529.

49. Somervaille LJ. In-vivo measurement of tibia lead levels by X-ray fluorescence. University of Birmingham, Birmingham England 1984. (Doctoral dissertation).

50. Somervaille LJ, Chettle DR, Scott MC. In-vivo measurement of lead in bone using $\mathrm{X}$-ray fluorescence. Phys Med Biol 30 (1985) 929-943.

51. Somervaille LJ, Laird EE, Chettle DR, Scott MC. Lead body stores assessed in vivo by X-ray fluorescence. In: CEP Consultants. Proceedings international conference heavy metals in the environment, Heidelberg 1983. Edinburgh 1983, pp 521-524.

52. Thomas BJ, Vartsky D, Hawkes DJ, Fremlin JH. An investigation of nuclear resonance scattering for in-vivo analysis of liver copper. J Radioanal Chem 37 (1977) $369-373$.

53. Tohyama C, Shaik ZA, Ellis KJ, Cohn SH. Urinary metallothionein as a biological indicator of occupational cadmium exposure. In: Wilson D, Volpe RA, ed. Proceedings 3 rd international cadmium conference, Miami 1981. Cadmium Association, London 1982, pp 180-183.

54. Vartsky D, Ellis KJ, Hull DM, Cohn SH. Nuclear resonant scattering of gamma-rays - A new technique for in-vivo measurement of body iron stores. Phys Med Biol 24 (1979) 689-701.

55. Vartsky D, Thomas DJ, Hawkes DJ, Fremlin JH. A preliminary investigation of nuclear scattering as a new technique for the in-vivo measurement of hepatic copper. Phys Med Biol 21 (1976) 970-975.

56. Vartsky D, Wielopolski L, Ellis KJ, Cohn SH. The use of nuclear resonant scattering of gamma rays for in-vivo measurement of iron. Nucl Instrum Methods 193 (1982) $359-364$.

57. Vartsky D, Wielopolski L, Ellis KJ, Cohn SH. A facility for in-vivo measurement of lithium. Neurotoxicology 4 (1983) 169-172.

58. Wielopolski L, Ancona RC, Mossey RT, Vaswani AN, Cohn SH. Nuclear resonance scattering measurement of human iron stores. Med Phys (in press).

59. Wielopolski L, Rosen JF, Slatkin DN, Vartsky D, Ellis $\mathrm{KJ}$, Cohn SH. Feasibility of non-invasive analysis of lead in the human tibia by soft X-ray fluorescence. Med Phys 10 (1983) 248-251.

60. Wielopolski L, Slatkin DN, Vartsky D, Ellis KJ, Cohn $\mathrm{SH}$. Feasibility study for the in-vivo measurement of lead in bone using L-X-ray fluorescence. IEEE Trans Nucl Sci NS-28 (1981) 114-116.

61. Wielopolski L, Vartsky D, Yasumura S, Cohn SH. Invivo measurement of strontium in human bone by X-ray fluorescence (XRF). Adv X-ray Anal 26 (1983) 415-421.

62. World Health Organization. Use of ionizing radiation and radionuclides on human beings for medical research, training and non medical purposes. Geneva 1977. (WHO technical report series 611 ).

Received for publication: 5 August 1985 